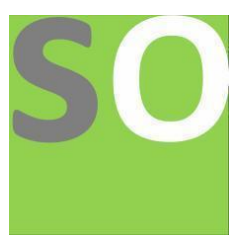

Article title: The Relationship Between Emotional Intelligence, Relationship Satisfaction And Anger Authors: Ankita Pritamani[1]

Affiliations: Psychology, VES College, Mumbai, India[1]

Orcid ids: 0000-0001-7350-9906[1]

Contact e-mail: ankita.pritamani@gmail.com

License information: This work has been published open access under Creative Commons Attribution License $\mathrm{http}: / / c r e a t i v e c o m m o n s . o r g / l i c e n s e s / b y / 4.0 /$, which permits unrestricted use, distribution, and reproduction in any medium, provided the original work is properly cited. Conditions, terms of use and publishing policy can be found at https://www.scienceopen.com/.

Preprint statement: This article is a preprint and has not been peer-reviewed, under consideration and submitted to ScienceOpen Preprints for open peer review.

DOI: 10.14293/S2199-1006.1.SOR-.PP7TSMM.v1

Preprint first posted online: 08 June 2021

Keywords: relationship satisfaction, emotional intelligence, anger, emotion, correlation, relationship 
THE RELATIONSHIP BETWEEN EMOTIONAL

INTELLIGENCE, RELATIONSHIP SATISFACTION

AND ANGER

A DISSERTATION SUBMITTED

TO THE

UNIVERSITY OF MUMBAI

FOR THE

M.A. (CBCS) DEGREE

IN

PSYCHOLOGY

(FACULTY OF HUMANITIES)

SUBMITTED BY

Ms. Ankita Pritamani

UNDER THE GUIDANCE OF

Dr. Madhu Rai

V. E. S. COLLEGE OF ARTS, SCIENCE AND COMMERCE

MAY 2020 
M.A.

(CBCS)

Ankita

Pritama

ni

MAY

2020 


\title{
THE RELATIONSHIP BETWEEN EMOTIONAL INTELLIGENCE, RELATIONSHIP SATISFACTION AND ANGER
}

\author{
A Dissertation submitted \\ to the \\ University of Mumbai \\ for the \\ M.A. (CBCS) Degree \\ in \\ Psychology \\ (Faculty of Humanities)
}

Submitted by

Ankita Pritamani

Under the Guidance of

Dr. Madhu Rai

\section{E. S. COLLEGE OF ARTS, SCIENCE AND COMMERCE}

May 2020

Signature of Guide

Signature of Principal

Dr. Madhu Rai

Dr. Anita Kanwar 
Emotional Intelligence, Relationship Satisfaction and A n g e r.

\section{Statement by the Candidate}

As required by the University Ordinance 770, I wish to state that the work embodied in this dissertation titled "The Relationship between Emotional Intelligence, Relationship Satisfaction and Anger" forms my own contribution to the research work carried out under the guidance of Dr. Madhu Rai at V. E. S. College Of Arts, Science and Commerce. This work has not been submitted for any other degree of this or any other University. Whenever references have been made to previous works of others, it has been clearly indicated as such and included in the Bibliography.

Signature of candidate

Ms. Ankita Pritamani

\section{Certified by}

Signature of Guide

Dr. Madhu Rai

Date: June 06, 2020 
Emotional Intelligence, Relationship Satisfaction and A n g e r.

Declaration

The work presented in this dissertation has been conducted by me under the guidance of Dr. Madhu Rai, Visiting Faculty, V. E. S. College Of Arts, Science and Commerce.

The observations, analysis, and interpretations made in the study as well as the conclusions arrived at and included in the dissertation are entirely my own.

The work reported in this is original and to the best of my knowledge, has not been submitted in part/full for any other diploma or degree of the University of Mumbai, or any other University, or Institute.

Signature of Guide Signature of Candidate

Dr. Madhu Rai

Ms. Ankita Pritamani

Date: June 06, 2020 


\section{Acknowledgement}

There are no proper words to convey my deep gratitude and respect for my thesis and research advisor, Dr. Madhu Rai. She has inspired me to become an independent researcher and helped me realize the power of critical reasoning. She demonstrated what a brilliant and hard-working researcher can accomplish. The door to Dr. Rai's office was always open whenever I ran into a trouble spot or had a question about my research or writing.

My sincere thanks must also go to the members of my college: Dr. Gayathri Balasubramanian, Prof Aankeet Gokkalgandhi and Ms. Ashwini Date. They generously gave their time to offer me valuable comments towards improving my work. In particular, Prof. Gokkalgandhi showed me the great power and potential of applying the right statistical tools to infer results. He provided me with constructive criticism which helped me develop a broader perspective to my thesis. I am most grateful to them for lending me their expertise and intuition to my theoretical and technical problems. I would also like to acknowledge the administrate staff at VES College for not only for their prompt support but also for their kind care.

I would like to express my gratitude to Dr. Nicola Schutte, Dr. Espen Røysamb and Dr. Bruce Sharkin for their permission to use the scales administered in this study and their counsel while using the scale correctly. 
Emotional Intelligence, Relationship Satisfaction and A n g e r.

I cannot forget friends who went through hard times together, cheered me on, and celebrated each accomplishment.

I deeply thank my family for their unconditional trust, timely encouragement, and endless patience. It was their love that raised me up again when I got weary. They have loved, supported, encouraged, entertained, and helped me get through this trying period in the most positive way.

My parents, siblings and friends were my pillars of strength during the Covid-19 pandemic; while I worked on and completed this thesis.

\section{Ankita Pritamani}

Author 


\section{Abstract}

The relationship between emotional intelligence, relationship satisfaction and anger was examined among couples who were in a relationship. There were 150 participants (Males $=34$; Females $=116$ ) between the ages of 25 and 60 . All the participants completed The Assessing Emotions Scale, The Relationship Satisfaction Scale and The Anger Discomfort Scale. To calculate the correlation between the variables, Spearman's rho was deployed. The results indicated a positive correlation between emotional intelligence and relationship satisfaction and a negative correlation between emotional intelligence and anger and relationship satisfaction and anger. Correlations between the four aspects of emotional intelligence with relationship satisfaction were also drawn; and once again the results showed a positive correlation between the variables. 
Emotional Intelligence, Relationship Satisfaction and A nger.

\section{CONTENTS}

\begin{tabular}{|c|c|c|}
\hline Chapter & Content & Page Number \\
\hline \multirow[t]{5}{*}{1} & Introduction & 1 \\
\hline & Rationale & 6 \\
\hline & Statement of the Problem & 6 \\
\hline & Significance of the Study & 6 \\
\hline & Aims and Objectives of the Study & 7 \\
\hline 2 & Review of Literature & 8 \\
\hline 3 & Methodology & 18 \\
\hline 4 & Results and Discussion & 23 \\
\hline 5 & Summary and Conclusion & 31 \\
\hline 5.1 & Summary & 31 \\
\hline 5.2 & Limitations & 31 \\
\hline 5.3 & Practical Implications & 32 \\
\hline 5.4 & Suggestions for Future Research & 32 \\
\hline & References & 34 \\
\hline
\end{tabular}




\section{LIST OF FIGURES}

Sr. No Table

Page Number

1 Pie Chart displaying the total population by segregating the number of males and females.

2 Scatter plot displaying the correlation between emotional intelligence and relationship satisfaction

3 Scatter plot displaying the correlation between perception of emotions and relationship satisfaction

$4 \quad$ Scatter plot displaying the correlation between managing own emotions and relationship satisfaction

5 Scatter plot displaying the correlation between managing others

emotions and relationship satisfaction

6 Scatter plot displaying the correlation between utilization of emotions and relationship satisfaction Scatter plot displaying the correlation between emotional intelligence and anger

8 Scatter plot displaying the correlation between relationship 
Emotional Intelligence, Relationship Satisfaction and A n g e r.

\section{LIST OF TABLES}

Sr. No Table

Page Number

1 Descriptive Statistics of variables.

24

2 Correlation between emotional intelligence and relationship

27

satisfaction.

3 Correlation between emotional intelligence and anger.

33

4 Correlation between relationship satisfaction and anger.

35 
Introduction

Emotional intelligence is a social intelligence that allows an individual to be in control of and monitor their own emotions as well as have a deep understanding of the emotions of others. Many researchers in the past decades have studies emotional intelligence and its impact on various aspects of our lives. It has been observed that emotional intelligence influences our personality, creativity and communication among other factors. However, the effects of emotional intelligence on relationship satisfaction and anger have not been explored as widely. This paper aims to understand the association between emotional intelligence, relationship satisfaction and anger in adults.

\subsection{Emotional Intelligence}

Emotional intelligence has a number of varied definitions. It has become a major topic for research and is widely explored in the scientific circles. Howard Gardner in his theory of multiple intelligences has defined emotional intelligence as the knowledge of one's own emotions and the knowledge of the emotions of others. Mayer et al., 2001 have divided emotional intelligence into four areas: a. perceiving emotions, b. using emotions to facilitate thought, c. understanding emotions and d. managing emotions in a way that enhances personal growth and social relations (Mayer et al., 2001). The facets of emotional intelligence include: management and regulation of emotions, adaptability, assertiveness, self esteem, low impulsiveness, self motivation, stress management, trait empathy, social competence, trait happiness, trait optimism, expression, perception and relationship skills (Smith et al., 2008). 
In a general sense, emotional intelligence posits that individuals are different in the way that they process, attend to, and utilize interpersonal and intrapersonal information (Petrides \& Furnham, 2003).

In the theory of emotional intelligence by John .D. Mayer et al., (Mayer et al., 2001), emotions are believed to contain information about relationships. Emotions hold a key to a person's relationships. When an individual's relationship with a person or an object changes, so do their emotions towards them. Whether a relationship is real or imagined, they are always accompanied by emotions. Here, emotional intelligence is the ability to understand these emotions and use them as a basis for reasoning and problem solving. As mentioned above, emotional intelligence is divided into four branches. While branches 1, 3, 4 are involved in the process of reasoning, branch 2 (using emotions to facilitate thought) uses emotions to enhance reasoning. The four branches are viewed as a hierarchy wherein emotional perception is at the bottom and management is at the top.

Another model of emotional intelligence was developed by Bar-On. He proposed that emotional intelligence is a system of interconnected behavior that arise from social and emotional competencies that have an influence on behavior (Faltas, 2017). This model includes 5 scales (self-perception, self-expression, interpersonal, decision-making, and stress management) and 15 sub-scales (self-regard, self-actualization, emotional self-awareness, assertiveness, impulse control, independence, empathy, social responsibility, problem- 
solving, emotional expression, interpersonal relationship, reality testing, flexibility, stress tolerance, and optimism, driving human behavior and relationships.) (Faltas, 2017).

Research has shown that emotional intelligence can predict happiness, satisfaction, success and even personality. Individuals with a high emotional intelligence believe that they are in touch with their emotions and are able to manage and assess their own emotional states. These individuals are found to be happier than other individuals (Furnham, A., \& Petrides, K. V. 2003).

\subsection{Emotional Intelligence and Relationship Satisfaction}

Attainting and maintaining a good healthy romantic relationship is considered to be the nucleus of a well adjusted individual (Hazan \& Shaver, 1990). For most adults; cohabitating, whether by marriage or not, amounts to a major portion of their social life. A good relationship leads to better life satisfaction and lower rates of depression. A good relationship also has beneficial effects under stressful situations and strains (Gun-Mette B Røsand, Kari Slinning, Malin Eberhard-Gran, 2012). Marital satisfaction deeps on an individual's needs and desires in the marriage. In a marriage, when one individual gets angry, he can use his emotional intelligence to navigate through those feelings and understand the feelings of his/her partner (Zarch et al., 2014). Being able to understand the emotions of others and being able to assist others regulate their mood help individuals form better and long lasting relationships. Therefore it is expected that individuals who have a higher 
emotional intelligence are more likely to have greater relationship and marital satisfaction (Schutte et al., 2001).

In a study done by Schutte (Schutte et al., 2001), it was found that emotional intelligence is strongly associated to interpersonal relationships. The higher emotional intelligence yields higher marital satisfaction. The study found that qualities such as empathy, cooperation and good social skills are all associated to emotional intelligence and vouchsafe greater relationship satisfaction. In the anatomy of a long lasting successful marriage, marital satisfaction is a variable that must be studied.

\subsection{Emotional Intelligence and Anger}

Anger is an extremely powerful emotion and is seen to exist in all living species, both humans and animals. Anger is a feeling that is experienced when an individual feels that his interests are being disrespected or violated by another person. Aggression on the other hand is a response that often stems from angry thoughts and feelings (Henriques Gregg) Anger is sometimes viewed as a substitute emotion that people feel when they do not want to feel other things; like pain. People change their feeling of pain to anger because it is easier to feel anger than it is to feel pain. Being angry acts as a huge distracter from other feelings that an individual can experience. Low agreeableness and high neuroticism have been found to predict higher levels of aggression in individuals through an increase of negative emotions such as anger (García-Sancho, E., Dhont, K., Salguero, J. M., \& Fernández-Berrocal, 2017). 
Emotional intelligence is the ability to understand one's own emotions and the emotions of others and use this knowledge to make better decisions and act in more appropriate ways. Not all individuals respond to anger by behaving in an aggressive way. Recent studies have shown that people with higher Ability Emotional Intelligence are less likely to engage in aggressive behavior than people with lower Ability Emotional Intelligence (García-Sancho et al., 2014). Ability Emotional Intelligence has also been shown to be negatively associated with anger rumination (Garcia-Sancho, E., Salguero, J. M. \& Fernandez-Berrocal, 2017).

(Hülya ŞAHİN BALTACI, 2012) In another study by Hülya Şahin Baltaci and Kemile Demir; pre-service classroom teachers had their emotional intelligence and anger expression style tested. Results of the study showed that those with higher emotional intelligence were able to control their anger instead of suppressing it or acting out.

Contrary to the study above; Brett Q. and Maya Tamir (Ford \& Tamir, 2012) found that emotionally intelligent people are better able to cope with their anger. Individuals who show that they want to feel angrier than others are found to be more emotionally intelligent when anger is more likely to serve them well. In contrast; people who want to feel happier than others are actually lower on the emotional intelligence quotient. This shows that wanting to feel good at all times may not be emotionally intelligent. 


\subsection{Relationship Satisfaction and Anger}

Humans experience a wide array of emotions through their relationships; where a happy and satisfying relationship yields joy and content whereas a dissatisfying relationship causes anxiety, loneliness and depression (Guerrero, 1994). One of the strongest feelings experienced in a relationship is anger. (Guerrero, 1994). Anger is experienced when someone feels that they have been wronged. Anger has been seen among romantic partners. Couples often seek therapy due to some kind of aggression in their relationship (Holtzworth-Munroe et al., 1997).

The paper Managing Anger for Better Health and Relationships (Sandra J. Bailey, 2011) stated that anger rears up most of the time in a relationship. Couples who show more verbal aggression have lesser relationship satisfaction. Couples who are better able to manage their anger in a positive way are more satisfied in their relationship.

Anger is expressed in various forms ranging from glaring to slamming doors. The expression of anger can lead to a conflict, result from a conflict, or be expressed during the course of a discussion that is not conflict-laden (Guerrero, 1994). In a study by Lie Liu et al (Liu, J., Lemay, E. P., \& Neal, 2018) it was found that when partners were fighting with each other; they indulged in more destructive behaviors towards each other which in turn elicited anger from the partner. In conclusion, expression of anger in any form is considered to be threatening and can cause significant troubles in a relationship if not managed well. 
1.5 Rationale

Emotional intelligence is commonly studied in regards to organizational management, leadership, power and performance. However, it is not commonly studied in regards to its relationship with relationship satisfaction and anger.

Emotional intelligence is developed over the course of one's life and can be influenced by various factors including age, gender and other demographics. Emotional intelligence and its relation to satisfaction in a relationship and anger need to be explored to delve the impact emotional intelligence has on these interpersonal variables.

\subsection{Statement of the Problem}

This study explores the relationship between emotional intelligence, relationship satisfaction and anger.

\subsection{Significance of the Study}

This study aims to explore the relationship between emotional intelligence, relationship satisfaction and anger. The study aims to find the correlation between the above mentioned variables and understand their influence on each other. Humans are emotional beings and therefore their emotional intelligence plays a significant role in all aspects of their 
8|Emotional Intelligence, Relationship Satisfaction and Anger.

life. This study aims to understand the influence of emotional intelligence of individuals on their relationship satisfaction and anger.

1.8 Aims and Objectives of the Study

The aim of this study is to explore the relationship between emotional intelligence, relationship satisfaction and anger. 


\section{Review of Literature}

In the study; 'Trait emotional intelligence, conflict communication patterns, and relationship satisfaction' (Smith et al., 2008) the relationship between emotional intelligence, conflicting communication patterns and relationship satisfaction among cohabitating couples was examined. 82 heterosexual couples participated in this study and filled three questionnaires: TEIQue - Short Form (Petrides \& Furnham, 2006), the Communication Patterns Questionnaire (Christensen \& Sullaway, 1984), and the Perceived Relationship Quality Components (PRQC) Inventory (Fletcher, Simpson, \& Thomas, 2000). Couples who did not avoid conflicting conversations showed most relationship satisfaction. In addition, those satisfied couples rated each other higher on emotional intelligence. Satisfied couples were more likely than dissatisfied couples to also rate themselves higher on emotional intelligence. The study found that the most satisfied couples are not those who avoid conflicts and see each other as having similar emotional intelligences.

In the study; 'Intimate Partner Aggression and Relationship Satisfaction across Attachment Styles' (Bonneville, 2016) the relationship satisfaction and intimate partner aggression across attachment styles was examined. The study included 170 participants. The study found that relationship length affected relationship satisfaction. The participants completed the attachment style questionnaire (Fraley, Waller, and Brennan, 2000), partner aggression frequency (Quigley, Daniels, Polihronis, and Magner \{2013\}), and dyadic adjustment scale (Spanier, 1976). The study found that fearful attachment styles are at most risk of engaging in verbal and relational aggression. Secure attachment styles showed the most relationship satisfaction whereas fearful attachment styles showed the lowest 
relationship satisfaction.

The study 'The buffering effect of relationship satisfaction on emotional distress in couples' (Gun-Mette B Røsand, Kari Slinning, Malin Eberhard-Gran, 2012) aimed to understand the risk factors for distress in heterosexual couples with a focus on relationship satisfaction. The study aimed to understand risk factors (individual and spousal) for emotional distress. It examined the extent to which relationship satisfaction would be helpful during times of distress. The study included 62,956 couples. The couples were asked to fill questionnaires about emotional distress, relationship satisfaction and other factors. For measuring emotional distress; a short version of the Hopkins Symptom Checklist (SCL-25) was administered. The 10-item Relationship Satisfaction (RS10) scale was administered to measure relationship satisfaction. A 4-item short version of the Rosenberg Self-Esteem Scale (RSE) was administered to measure self esteem and a checklist was used to obtain details about the women's somatic symptoms and illnesses. The study concluded that relationship satisfaction is majorly associated with emotional distress for both; men and women. If a good partnership is perceived by both; the male and female: it reduces the strain of emotional distress.

The study 'Personality, Emotional Intelligence and Marital Satisfaction of Violent and Non-Violent' (Tejbeer Kaur and Gurminder Sokhey, 2011) aimed to examine personality patterns, emotional intelligence and marital satisfaction among violent and non-violent couples. The study included 30 couples. The Big five inventory, Emotional Intelligence Scale 
(Hyde \& Pethe, 2001) and Marital Satisfaction (ENRICH Couple Scales) were administered to the participants in the study. This study hypothesized that violent couples will score higher on neuroticism and lower on emotional intelligence and marital satisfaction as compared to non-violent couples. The study yielded that the perpetrators have learnt violence as a dysfunctional response because of witnessing violence in their families at a younger age. The study concluded that various factors lead to higher levels of neuroticism, lack emotional stability and therefore create a negative cycle for themselves.

In the study 'Anger in Close Relationships: An Interpersonal Script Analysis' (Fehr et al., 1999), an analysis of anger scripts in close relationships from a relational schema perspective while focusing on the sequencing of anger events and interpersonal experience of anger was done. The amount of anger resulting from various events was found to be different in men and women. Students of introductory psychology at University of Winnipeg participated in this study. It included 51 men and 73 women. $24.2 \%$ of the participants indicated that they were not currently dating or romantically involved, $28.2 \%$ were casually dating, $3.2 \%$ were engaged, $4 \%$ were cohabiting, $31.5 \%$ were seriously or exclusively involved, 5.6\% were married, and 3.2\% selected the category "other" (e.g., divorced, widowed). The study included three parts; the first included a questionnaire to assess degree of anger cause by various different stimuli. The second part included the possible reactions when angry and part three anticipated a partner's response to self's expression of anger using a questionnaire. Results indicated that women and men react differently to anger events. Women are more likely to respond with indirect aggression. Men were more likely than women to anticipate a response to anger of various kinds. Women expected men to respond 
to anger by talking it over. Men expected their partners to express hurt feelings and reject them whereas women expected to be mocked. Overall in the study; people anticipated that they would smooth things over by talking about it rather than expressing anger.

In the study 'The stability and change of trait emotional intelligence, conflict communication patterns, and relationship satisfaction: A one-year longitudinal study' (Lynne Smith, Joseph Ciarrochi, 2008), 45 heterosexual couples were administered the TEIQue Short Form (Petrides \& Furnham, 2006), the Communication Patterns Questionnaire (Christensen \& Sullaway, 1984), and the Perceived Relationship Quality Components (PRQC) Inventory (Fletcher, Simpson, \& Thomas, 2000). These couples were studied for 12 months. The change in trait emotional intelligence, relationship satisfaction and conflicting communication patterns were examined. The research showed that for individuals, their self rated emotional intelligence on their own satisfaction remained stabled over the 12 month period. One unexpected finding was that individuals who reported who reported greater satisfaction the first time has partners who reported lesser satisfaction the second time around. The results also showed that in females; withholding communication lead to lesser satisfaction for themselves and their partner.

The study 'Emotional Intelligence, Attachment and Satisfaction with Romantic Relationships among Young Adults: A Brief Report' (Zysberg, L., Kelmer, G., \& Mattar, 2019) aimed to test the roles of emotional intelligence and attachment styles in romantic relationships. The scales for this study were administered to 175 young adults from Israel. 
The ENRICH (Nurturing Relationship Issues Communication \& Happiness; Olson, Fournier, \& Druckman, 1982) was used to measure relationship satisfaction, AVEI (Audio visual test of emotional intelligence; Zysberg, Levy and Zisberg, 2011) was used as a test of emotional intelligence and the ECR (Experience in Close Relationship Scale; Brennan, Clark, \& Shaver, 1998) was administered to assess attachment styles. The study revealed that there is a relationship between emotional intelligence and relationship satisfaction only when they are studied in terms of emotional attachment. The study further revealed the role of emotional intelligence in terms of romantic relationships. Both- avoidant and anxious attachment styles showed a negative relation to satisfaction and emotional intelligence showed a positive association to both.

The study 'Emotional Intelligence and Marital Satisfaction' (Lavalekar, A., Kulkarni, P., \& Jagtap, 2010) aimed to examine the relationship between emotional intelligence and marital satisfaction. The tools were administered to 316 respondents between the ages of 25 to 65. The Marital Satisfaction Scale (MSS) and Exploring Emotional Abilities (EEA) were administered to the participants. The results indicate that individuals who score lower on emotional intelligence have a possibility of having lesser satisfaction in their marriage. The study concludes a positive relationship between emotional intelligence and relationship satisfaction. Individuals who were satisfied in their relationships outscored those who were unsatisfied in their relationship in terms of emotional intelligence.

In the study; 'Intimacy-Anger and Insecure Attachment as Precursors of Abuse in 
Intimate Relationships' (Donald G. Dutton, Keith Saunders, Andrew Starzomski, 1994), men who were referred for treatment for assaulting their wives were administered questionnaires that assessed attachment patterns, anger, jealousy, Borderline Personality Organization, and trauma symptoms. It was assumed that these symptoms are associated with the frequency of verbal and physical abuse. The study included 120 men who entered the Vancouver Assaultive Husbands Program and the Victoria Family Violence Project. They were administered these scales either before treatment began or during the initial 3 weeks of treatment. The Relationship Styles Questionnaire (RSQ) (Griffin \& Bartholomew, 1994), Bartholomew and Horowitz's (1991) Relationship Questionnaire, and Collins and Read's (1990) Adult Attachment Scale were administered to assess attachment styles. Borderline Personality Organization (Oldham et al., 1985) was administered to assess Borderline Personality Organization, The Multidimensional Anger Inventory (MAI; Siegel, 1986) was used to assess anger, The Interpersonal Jealousy Scale (Mathes, Phillips, Skowran, \& Dick, 1982; Mathes \& Severa, 1981) was administered for the assessment of jealousy, The Trauma Symptoms Checklist (TSC33; Briere \& Runtz, 1989) was administered to assess symptoms of trauma and Tolman's (1989) Psychological Maltreatment of Women Inventory (PMWI) was administered for a deeper understanding of abuse. The treatment group men scored significantly higher than a control group on Borderline Personality Organization, Multidimensional Anger Inventory (anger), jealousy, and Trauma Symptom Checklist-33 (trauma symptoms) total scores. Significant and positive scores were found on fearful attachment styles and BPO, anger, trauma symptoms and jealousy. Fearful attachment also strongly correlated significantly with scores on both the dominance /isolation and emotional abuse factors. 
In the study; 'Marital Interaction and Satisfaction: A Longitudinal View' (Gottman, J. M., \& Krokoff, 1989), two longitudinal studies were conducted using observations of couples who were attempting to resolve high conflict issues. The study included 25 couples. To study marital satisfaction and the changes in marital satisfaction, the Locke-Wallace (Locke \& Wallace, 1959) and the Locke-Williamson (Burgess et al., 1971) scales were administered to each spouse. For the observational part, the couples were recorded for a period of 15 minutes in their homes while they discussed conflict issues. The study revealed that conflicts about specific issues are beneficial in a marriage for the long run but issues of stubbornness and defensiveness may be harmful in the long run. The result of the study showed that certain issues such as anger and disagreement may not actually be bad in the long run. These things may lead to issues in the present but in the long run they show to improve marital satisfaction.

Since effective emotional communication and economic factors are both responsible for marital satisfaction, the study 'The Relationship between Emotional Intelligence and Marital Satisfaction: 10-Year Outcome of Partners from Three Different Economic Levels' (Zarch et al., 2014) aimed to investigate these variables over a 10 year period. 159 couples participated in this study. The Bar-on Emotional Intelligence (1997) and Enrich Marital satisfaction (1989) measures were used in this study. The economic classifications were: rich, semi-rich and under-rich. The highest scores for marital satisfaction and emotional intelligence were found in the under-rich group. The study found a significant relationship between all aspects of emotional intelligence and martial satisfaction except the interpersonal component. The results showed that higher the emotional intelligence, higher the marital 
satisfaction. In conclusion, this study found a significant relationship between all components of emotional intelligence and marital satisfaction in the rich, semi-rich and under-rich groups. Further analysis revealed that in the under-rich group, there is no significant relationship between the interpersonal component and marital satisfaction.

In the study; 'Anger and Anger's Expression Generally and in Romantic Relationships' (Kocur, J. L., \& Deffenbacher, 2014), the researchers explored whether anger and the expression of anger differed when experienced generally versus experienced in the context of a romantic relationship. The study included 383 participants; 109 male, 274 females ranging between the ages of 17 and 49. The Trait Anger Scale (TAS) (Spielberger 1988), the Anger Expression Scale (Spielberger 1988) and a Relationship Questionnaire were administered to the participants. Results showed that women showed more anger in relationships than men. Women reported more anger out forms of anger expression in relationships than in general, whereas men did not differ in their anger expression style as a function of context. Men showed more anger control in both contexts as compared to women. In general results did not show that more anger would be experienced in relationships than in general.

The study; 'The relationship between aggression and ability emotional intelligence: The role of negative affect' (A. Megıas, R. Gomez-Leal , M.J. Gutierrez-Cobo \& FernandezBerrocal, 2018) aimed to understand the relationship between aggression and emotional intelligence. The study included 395 participants. The participants were assessed on 
emotional intelligence, negative affect and aggression. The Mayer-Salovey-Caruso Emotional Intelligence Test, the Positive and Negative Affect Schedule, and the Buss-Perry Aggression questionnaires were adopted in this study. The results indicated a direct relationship between emotional intelligence and aggression. Emotional perception ability showed a indirect relationship with aggression through negative affect. The results also showed that women showed greater emotional intelligence as well as greater negative affect as compared to men.

The study; 'Trait Emotional Intelligence And Happiness' (Furnham, A., \& Petrides, 2003) aimed to examine the relationship between happiness and trait emotional intelligence. 88 individuals participated in this study. The tools used in this study included the NEO-FFI (Costa \& McCrae, 1992), Wonderlic Personnel Test (Wonderlic Personnel Test Inc., 1998), The Baddeley Reasoning Test (Baddeley, 1968), the AH5 - Part 1 (Heim, Watts, \& Simmonds, 1970), the WAIS Vocabulary Subscale (Wechsler, 1981), the Trait Emotional Intelligence Questionnaire Short Form (TEIQue-SF; Petrides, Pérez, \& Furnham, 2003) and The Oxford Happiness Inventory (Argyle, Martin, \& Crossland, 1989). The results show that both emotional intelligence and happiness were not correlated to any of the cognitive ability test. It was also established that in the presence of trait emotional intelligence, happiness was only related to openness. In the presence of trait emotional intelligence, the statistically associated of extraversion and neuroticism to happiness is eliminated.

The study; 'Explaining the Link Between Personality and Relationship Satisfaction: Emotion Regulation and Interpersonal Behaviour in Conflict Discussions' (Vater, A., \& Schröder- 
Abé, 2015) examined the role of emotional regulation in interpersonal behavior. The study included 137 couples. The study had three stages: first; questionnaire that the participants filled, second; a laboratory session that followed 2 weeks later and thirdly; a questionnaire at a 6 months follow-up at home. The first questionnaire assessed the Big Five personality traits. In the follow up 6 months later, the participants completed a questionnaire regarding their relationship satisfaction. The Relationship Assessment Scale (RAS, Hendrick, 1988; German Version: Sander \& Böcker, 1993) was deployed to assess satisfaction. The results showed that higher scores on extraversion, openness, conscientiousness and agreeableness is associated with better emotional regulation and therefore yields greater relationship satisfaction. The results also show that suppression of emotional and externalizing during a conflict; both lead to lower relationship satisfaction. The study draws a link between relationship satisfaction and personality patterns.

The study; 'Women And Anger: Sex And Sex-Role Comparisons In The Expression Of Anger' (Kopper, B. A., \& Epperson, 1991) aimed to investigate the relationship of sex and sex-role identity with the expression of anger. Women's experiences and expressions of anger were studied empirically. There is a prevailing belief that women experience and express anger differently from men. This study included 455 undergraduate students: 242 women and 213 men who were students of a university. The Trait Anger Scale (Spielberger, 1980), Anger Expression Scale (Spielberger, 1986), Bem Sex-Role Inventory-Short Form (Bern, 1981), and a demographic questionnaire were administered to all the participants of the study. The results indicated that sex was not a determining factor in the expression of anger or in the tendency to suppress anger. In contrast; sex-role identity was found to be 
19|Emotional Intelligence, Relationship Satisfaction and Anger.

significantly associated with anger proneness, control of anger and expression of anger towards people or objects in the environment. The results showed that women did not suppress their anger more than men and neither did feminine sex-role suppress more anger than masculine sex-roles. 
Method

\subsection{Research Questions}

What is the correlation between Emotional Intelligence, Relationship Satisfaction and Anger?

\subsection{Hypotheses}

HO: There is no significant correlation between Emotional Intelligence, Relationship Satisfaction and Anger.

H1: There is a significant positive correlation between Emotional Intelligence and Relationship Satisfaction.

$\mathrm{H} 2$ : There is a significant negative correlation between Emotional Intelligence and Anger.

H3: There is a significant negative correlation between Relationship Satisfaction and Anger.

\subsection{Variables}

1. Emotional Intelligence

2. Relationship Satisfaction

3. Anger

\subsection{Operational Definitions}

Emotional Intelligence: Emotional intelligence is the ability to understand and manage one's own emotions as well as the emotions of others. Emotional intelligence includes four facets: perception of emotions, managing own emotions, managing others emotions and utilization of emotions. 
Relationship Satisfaction: Relationship satisfaction in the amount of positivity of feelings and emotions for one's partner and attraction to the relationship. Satisfaction is often assumed to be the highest during the initial years of marriage and declines later.

Anger: Anger is the most basic human emotion and is experienced by almost everyone. It can yield positive outcomes or lead to dysfunctional and aggressive behaviour. It involves hostility and antagonism towards someone whom an individual feels has wronged him. One of the more significant underlying psychological components of both anger experience and expression is the degree to which people feel uncomfortable with their own anger. Individuals who experience anger discomfort are threatened by their experience of anger and are concerned about the reaction of others to their anger.

\subsection{Participants}

The sample of this study includes males and females who are between the ages of 25 and 60 and in a relationship.

\subsection{Sample Size}

$\mathrm{N}=150($ Males $=34 ;$ Females $=116)$

The sample size of this study is 150 participants which includes 34 males and 116 females.

\subsection{Research Design}

This is a confirmatory research with a quantitative-correlational research design. 


\subsection{Sampling Method}

Two sampling methods were used in this study: the convenience based sampling method and the snowball sampling method. Convenience Sampling would be the primary form of sampling that would be used to send to the acquaintances of the author of this paper. Snowball Sampling would be employed by asking the acquaintances to send the link to their acquaintances with a request to pass it on to their acquaintances.

\subsection{Instrumentation}

a. Emotional Intelligence

The Assessing Emotions Scale was used as a measure of Emotional Intelligence. The scale is also called the Schutte Emotional Intelligence Scale. It is a 33 item scale. The scores are measured by summing all the scores and after reverse coding items 5, 28 and 33 . The total scores can range between 33 and 165 (Schutte et al., 2009).

The scale measures four aspects of emotional intelligence. Perception of Emotion (items 5, 9, 15, 18, 19, 22, 25, 29, 32, 33), Managing Own Emotions (items 2, 3, 10,

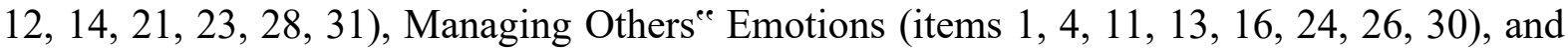
Utilization of Emotion (items 6, 7, 8, 17, 20, 27). All 33 items are included in one of these four subscales (Schutte et al., 2009).

The internal consistency of the scale was measures using Cronbach's Alpha and was found to be .90 . It has a test-retest reliability of .78 for total scale scores. The scores on the 
Assessing Emotions Scale were correlated with scores on the EQ-I with a substantial $r=.43$ (Schutte et al., 2009).

b. Relationship Satisfaction

The Relationship Satisfaction Scale was used as a measure for relationship satisfaction. The scale consists of 10 items. Items 2, 5 and 7 were reverse scored.

The reliability of the scale was measured using Cronbach's Alpha. A high internal validity was found. The test showed test-retest reliability. Convergent validity was evidenced by a high correlation with the Quality of Marriage Index (7) (Røysamb et al., 2014).

c. Anger

The Anger Discomfort Scale (Sharkin et al, 1991) was used as a tool to measure anger. It is a 15 item scale. Items 5, 10 and 11 are reverse scored in order to obtain a final total score. The scores can range between 15 and 60 .

To measure reliability, Cronbach's Alpha was performed. An internal consistency of $\alpha=.81$ was found. The test-retest coefficient was .87. The ADS correlated positively with anger-out $(\mathrm{n}=150, \mathrm{r}=.20, \mathrm{p}<.01)$, anger-in $(\mathrm{n}=150, \mathrm{r}=.32, \mathrm{p}<.001)$, and general anger expression $(\mathrm{n}=150, \mathrm{r}=.34, \mathrm{p}<.001)$. 


\subsection{Procedure}

The research uses survey method for collecting data. In order to gain access to the sample, an online questionnaire was developed. A link to a Google form containing the item pool was sent around for participants to fill. Using the convenience sampling method, the link was sent to the acquaintances of the author of this paper. The link was further distributed allowing the snowballing method to take effect. A consent form was included in the form and had to be filled before the participants could participate in the study. All eligible and willing participants were presented with a short message prior to the briefing page explaining briefly what the nature of the study is and what it is seeking to investigate. Within the briefing page participants were informed of their right to withdraw and also given some information regarding support services in case any content of the questionnaire raised difficult feelings. Participants were also given the researchers email address should they have any questions before or after completion of the survey. All participants administered the questionnaire (See in appendix) which took an average of ten minutes to complete.

\subsection{Inclusion and Exclusion Criteria}

This study includes individuals who are between the ages of 25 and 60, in a relationship and who are able to read and understand English. 
25|Emotional Intelligence, Relationship Satisfaction and A n g e r.

\subsection{Ethical Considerations}

The participants were informed about the nature of the survey to avoid discomfort during the course responding. They were assured of the maintenance of strict confidentiality and anonymity of their data. All of this along with a request to indicate informed consent would be presented in the Informed Consent form. Researcher's contact details were also provided for any queries a person might have at the end of their participation. 


\section{Results and Discussion}

The aim of this study was to find the relation between the Emotional Intelligence, Relationship Satisfaction and Anger in adults. The sample size of this study was 150 which included both males and females. In this study there were 34 males and 116 females. Majority of the population included individuals who were in a relationship of some form and between the ages of 25 and 60 .

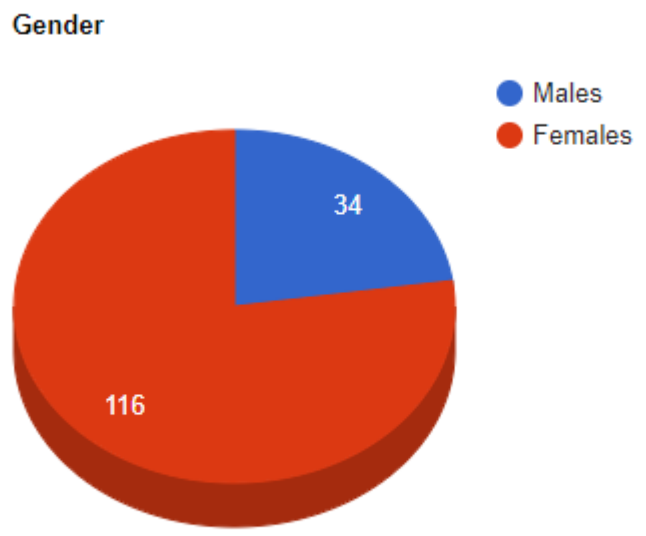

Fig 4.1 Pie Chart displaying the total population by segregating the number of males and females.

\subsection{Descriptive Statistics}

The following descriptive statistics will be calculated for each subscale and item: Mean and Standard Deviation. 
After collecting the data, the next step is to analyse the data statistically and interpret the findings at both statistical and theoretical levels. Collected data has been presented in a table form after calculating basic statistical factors like mean, median and standard deviation.

The statistical properties of the variable are depicted in Table 4.1 for the entire sample. The mean for Emotional Intelligence was 128.72 with SD 13.77. The mean for Relationship Satisfaction was 46.07 with SD 10.55. The mean for Anger was 39.17 with SD 8.67 .

\begin{tabular}{llll}
\hline & Mean & SD & $\mathrm{N}$ \\
\hline Emotional & 128.72 & 13.77 & 150 \\
Intelligence & & & \\
& & & \\
\hline Relationship & 46.07 & 10.55 & 150 \\
Satisfaction & & & \\
& & & \\
\hline Anger & 39.17 & 8.67 & \\
& & & \\
\hline
\end{tabular}

Table 5.1 Descriptive Statistics of Variables

4.2 Inferential Statistics

Correlation, as a form of inferential statistics was performed using Spearman's Rank Correlation to find whether there is a positive or a negative correlation between the variables 
of Emotional Intelligence, Relationship Satisfaction and Anger. The Spearman's Rank Correlation was used because the assumption of normality was not met; and therefore a nonparametric test of correlation was used. The correlation can range from -1 to $+1(-1 \leq r \leq+1)$. The R and SPSS software were used to calculate the statistical data.

\section{a. Emotional Intelligence and Relationship Satisfaction}

A correlation analysis was done to find out if Emotional Intelligence was significantly related to Relationship Satisfaction. The Spearman's rank correlation was calculated to find out the correlation between the variables. The Spearman's rank correlation, rho, can take a range of values from -1 to +1 . A value of 0 stipulates that there is no association between the two variables. A value greater than zero stipulates a positive association; that is, as the value of one variable increases, so does the value of the other variable. A value less than zero stipulates a negative association; that is as the value of one variable increases, the value of the other variable decreases.

The correlation results were in line with the hypotheses. It was hypothesized that individuals who have a higher emotional intelligence have greater relationship satisfaction. The correlation between the variables was found to be 0.257 which was significant at a $p=$ 0.001; which indicates a weak positive correlation.

Similar results were found in a study by Lynne Smith et al., (Smith et al., 2008) where the results indicated that over a course of a year, an individual's self-rated emotional intelligence has a significant effect on the satisfaction of the couple. In another study Nicola 

A n g e r.

S. Schutte et al., (Schutte et al., 2001) it was found that individuals who displayed higher emotional intelligence showed higher relationship satisfaction $[\mathrm{r}(36)=.51, \mathrm{p}<.0005$ (onetailed)].

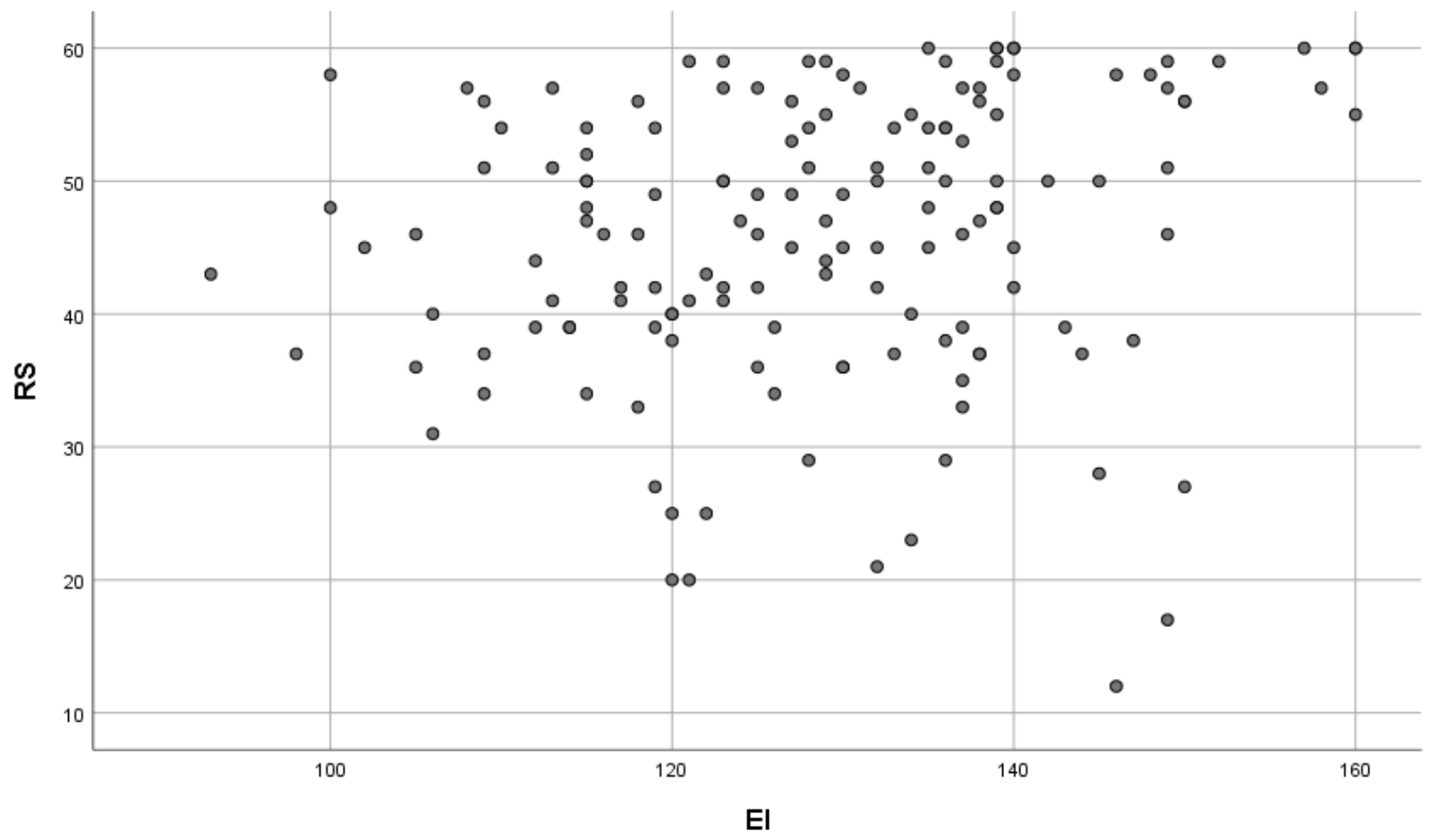

Fig 4.2 Scatter plot displaying the correlation between emotional intelligence and relationship satisfaction

The study by Lynne Smith et al (Lynne Smith, Patrick C.L. Heaven, 2008) showed that relationship satisfaction and emotional intelligence were positively correlated. Positive correlation was found between self-rated emotional intelligence and spouse rated emotional intelligence for both males and females. A weak-partial positive association was found between emotional intelligence and relationship satisfaction for men. The study also found a negative correlation between emotional intelligence and conflict communication patterns in general. 


\section{Correlations}

\begin{tabular}{|c|c|c|c|c|}
\hline & & & EI & $\mathrm{RS}$ \\
\hline \multirow[t]{6}{*}{ Spearman's rho } & EI & Correlation Coefficient & 1.000 & $.257^{* * *}$ \\
\hline & & Sig. (1-tailed) & & .001 \\
\hline & & $\mathrm{N}$ & 150 & 150 \\
\hline & RS & Correlation Coefficient & $.257^{* *}$ & 1.000 \\
\hline & & Sig. (1-tailed) & .001 & \\
\hline & & $\mathrm{N}$ & 150 & 150 \\
\hline
\end{tabular}

**. Correlation is significant at the 0.01 level (1-tailed).

Table 5.2 Correlation between emotional intelligence and relationship satisfaction.

A correlation analysis was done to find out if the Perception of Emotions aspect of Emotional Intelligence was significantly related to Relationship Satisfaction. The Spearman's rank correlation was calculated to find out the correlation between the variables. The correlation results were in line with the hypotheses. It was hypothesized that individuals who have higher scores on the Perception of Emotions aspect of Emotional Intelligence have greater relationship satisfaction. The correlation between the variables was found to be 0.1315484 which was significant at a $\mathrm{p}=0.05429$; which indicates a very weak positive correlation. 


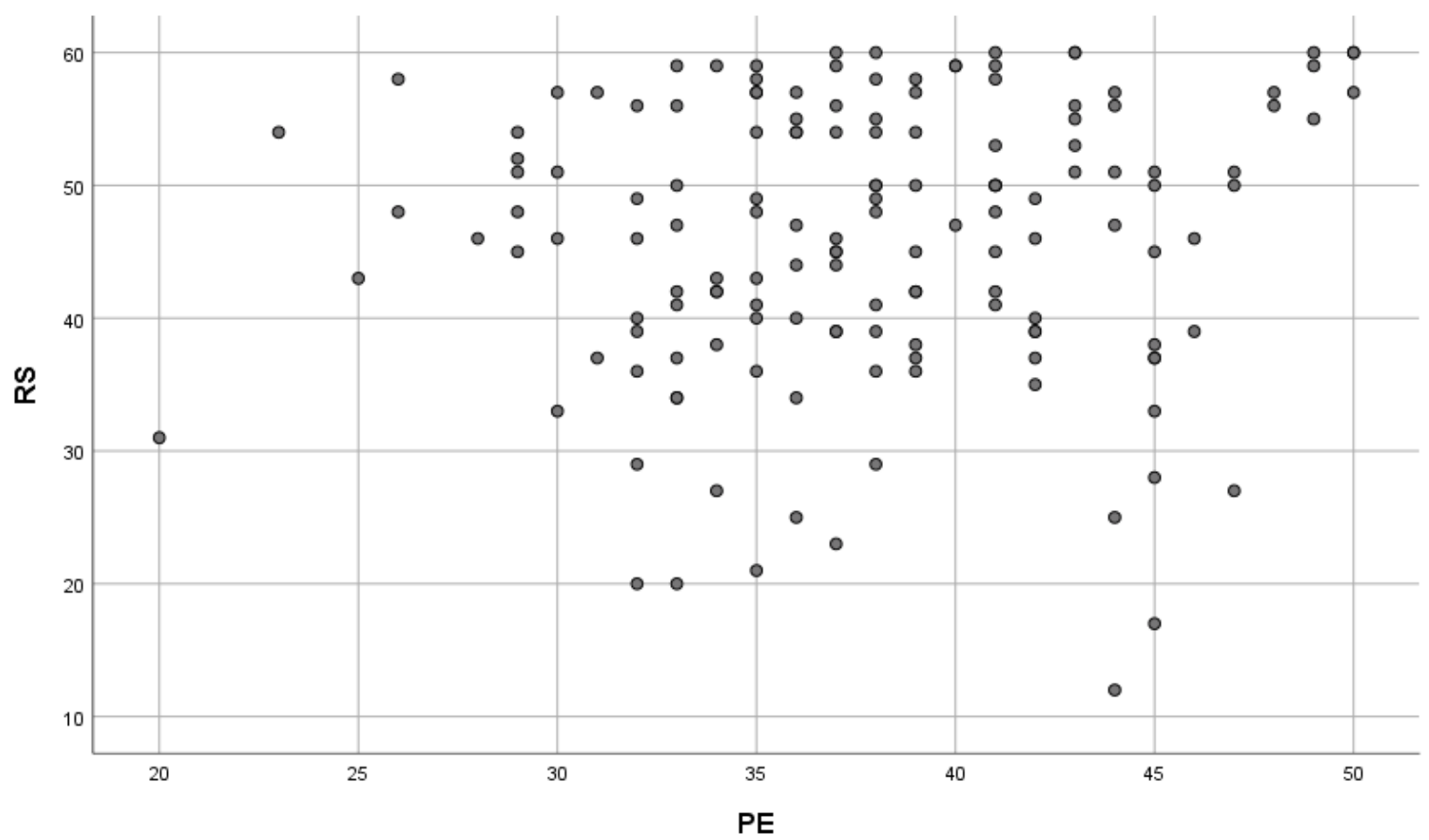

Fig 4.3 Scatter plot displaying the correlation between perception of emotions and relationship satisfaction

A correlation analysis was done to find out if the Managing Own Emotions aspect of Emotional Intelligence was significantly related to Relationship Satisfaction. The Spearman's rank correlation was calculated to find out the correlation between the variables. The correlation results were in line with the hypotheses. It was hypothesized that individuals who have higher scores on the Managing Own Emotions aspect of Emotional Intelligence have greater relationship satisfaction. The correlation between the variables was found to be 0.2834262 which was significant at a $\mathrm{p}=0.0002202$; which indicates a weak positive correlation. 


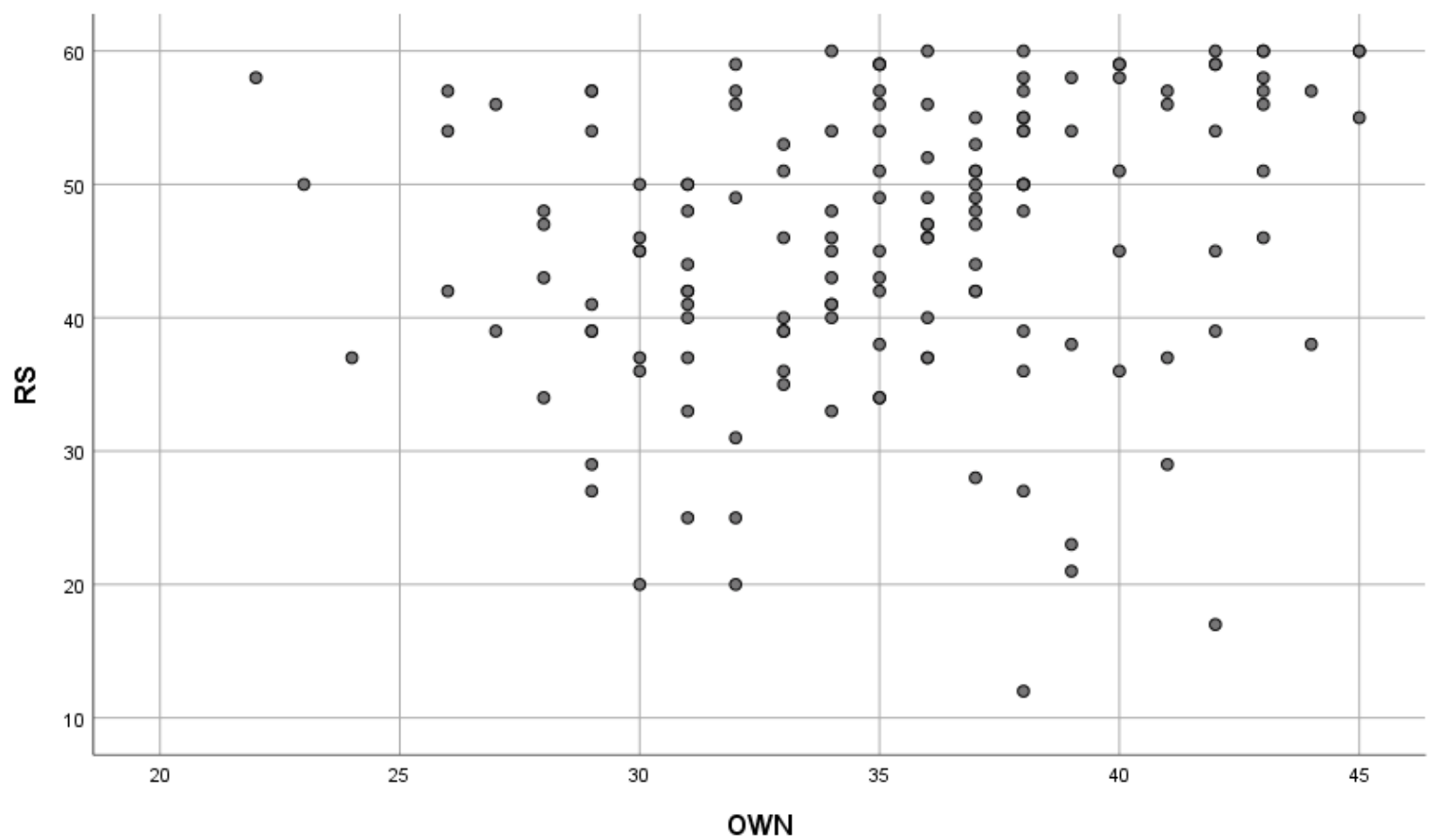

Fig 4.4 Scatter plot displaying the correlation between managing own emotions and relationship satisfaction

A correlation analysis was done to find out if the Managing Others Emotions aspect of Emotional Intelligence was significantly related to Relationship Satisfaction. The Spearman's rank correlation was calculated to find out the correlation between the variables. The correlation results were in line with the hypotheses. It was hypothesized that individuals who have higher scores on the Managing Others Emotions aspect of Emotional Intelligence have greater relationship satisfaction. The correlation between the variables was found to be 0.2534025 which was significant at a $\mathrm{p}=0.0008776$; which indicates a weak positive correlation. 


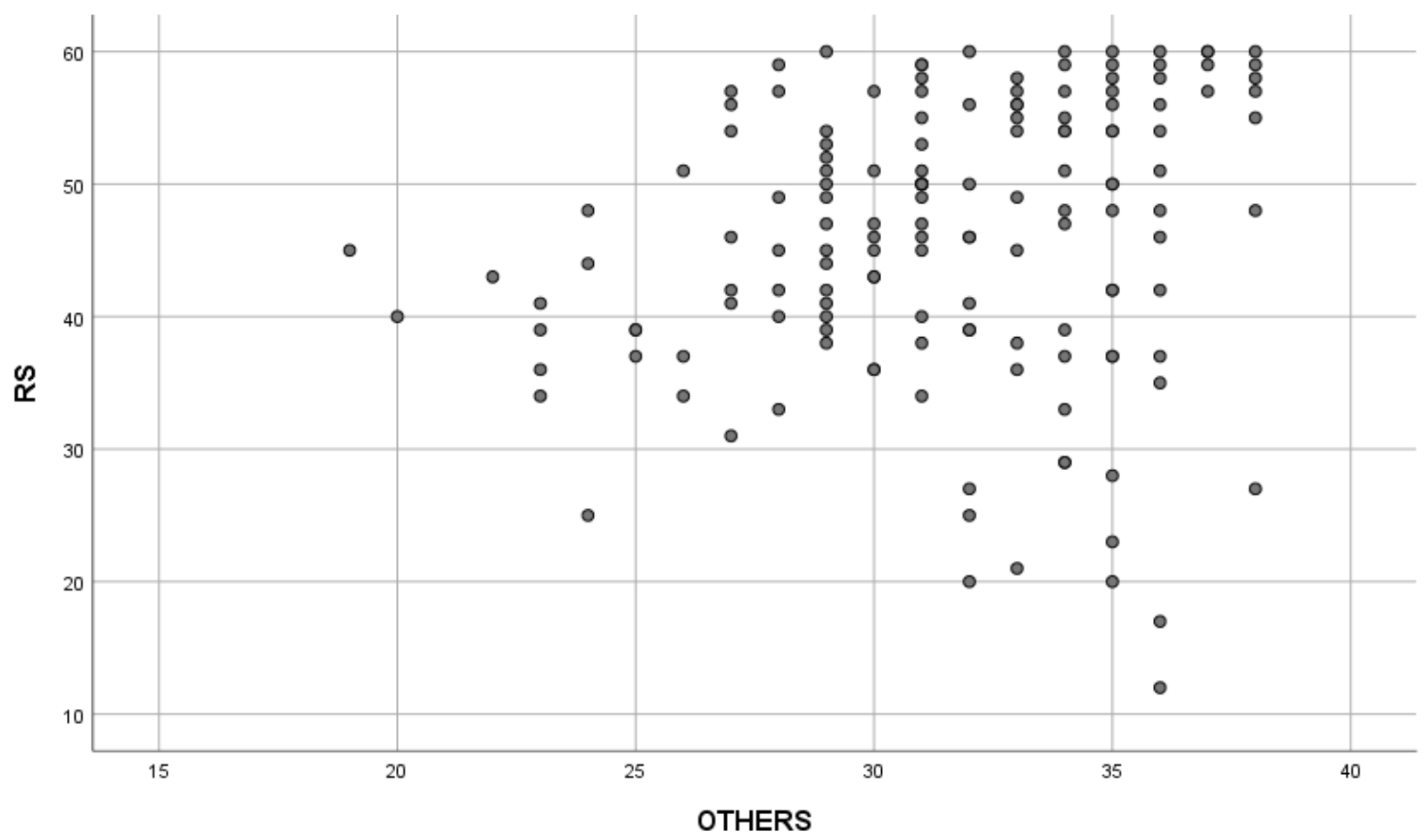

Fig 4.5 Scatter plot displaying the correlation between managing others emotions and relationship satisfaction

A correlation analysis was done to find out if the Utilization of Emotions aspect of Emotional Intelligence was significantly related to Relationship Satisfaction. The Spearman's rank correlation was calculated to find out the correlation between the variables. The correlation results were in line with the hypotheses. It was hypothesized that individuals who have higher scores on the Utilization of Emotions aspect of Emotional Intelligence have greater relationship satisfaction. The correlation between the variables was found to be 0.1403983 which was significant at a $\mathrm{p}=0.0433$; which indicates a very weak positive correlation. 


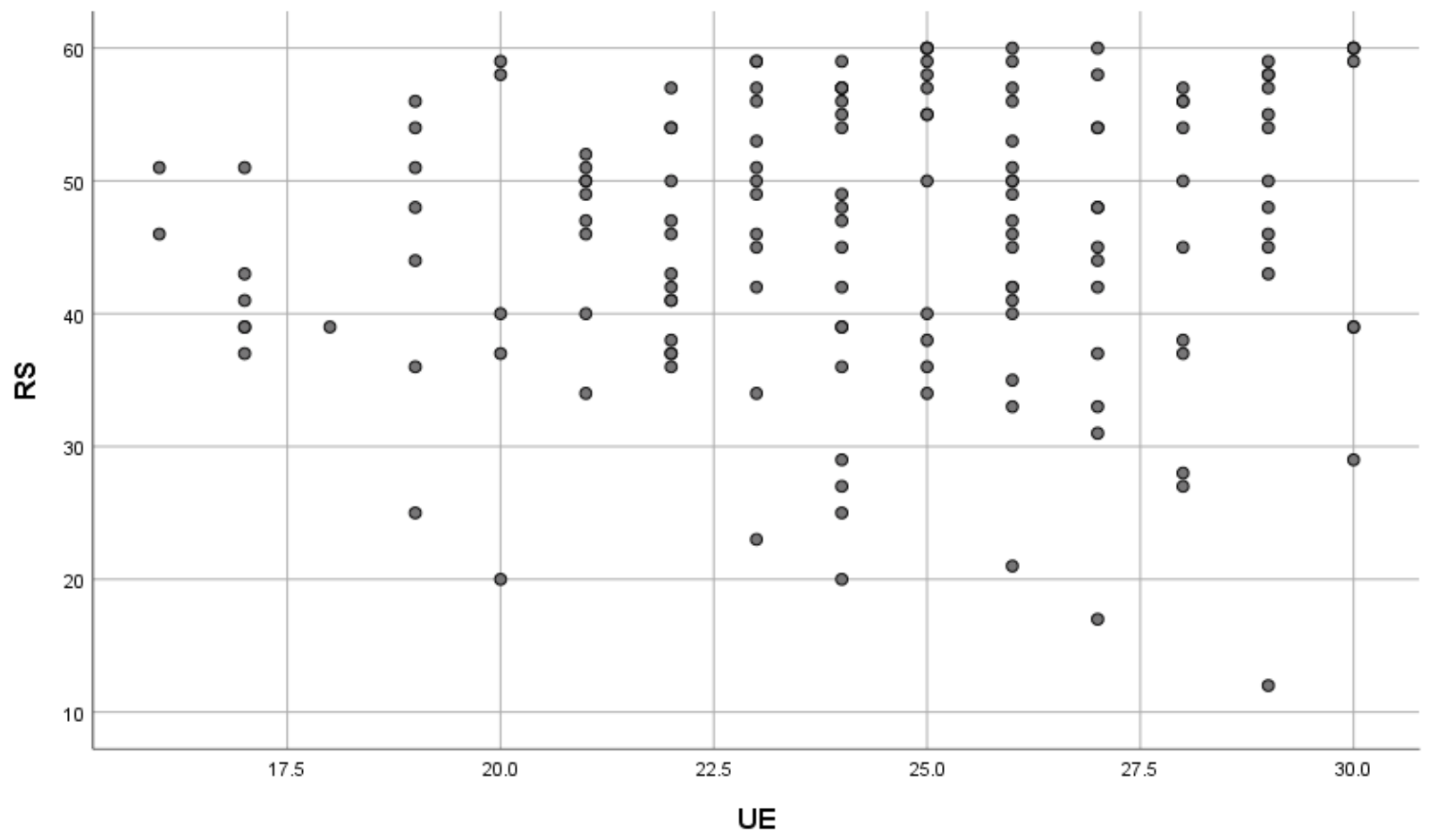

Fig 4.6 Scatter plot displaying the correlation between utilization of emotions and relationship satisfaction

\section{b. Emotional Intelligence and Anger}

A correlation analysis was done to find out if Emotional Intelligence was significantly related to Anger. The Spearman's rank correlation was calculated to find out the correlation between the variables. The Spearman's rank correlation, rho, can take a range of values from -1 to +1 . A value of 0 stipulates that there is no association between the two variables. A value greater than zero stipulates a positive association; that is, as the value of one variable increases, so does the value of the other variable. A value less than zero stipulates a negative association; that is as the value of one variable increases, the value of the other variable decreases. 
The correlation results were in line with the hypotheses. It was hypothesized that individuals who have a higher emotional intelligence will show lesser anger. The correlation between the variables was found to be -0.206 which was significant at a $p=0.006$; which indicates a weak negative correlation.

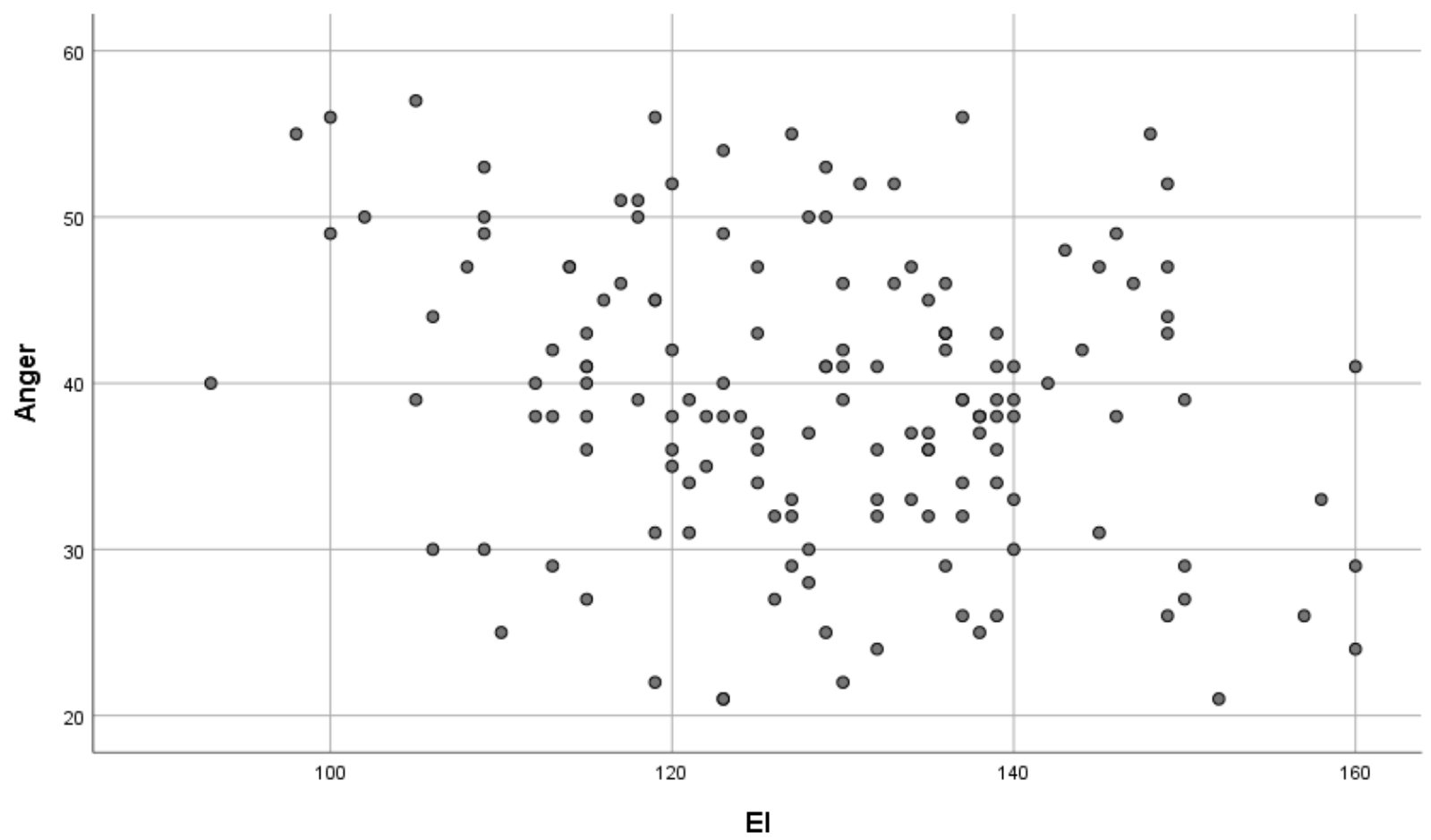

Fig 4.7 Scatter plot displaying the correlation between emotional intelligence and anger

Previous studies have shown that people with higher Ability Emotional Intelligence are less likely to engage in aggressive behavior than people with lower Ability Emotional Intelligence and can also buffer against the effects of anger on aggression (García-Sancho et al., 2014). Ability Emotional Intelligence has also been shown to be negatively associated with anger rumination (Garcia-Sancho, E., Salguero, J. M. \& Fernandez-Berrocal, 2017). 


\section{Correlations}

\begin{tabular}{lllll} 
& & EI & Ag \\
\hline Spearman's rho & EI & Correlation Coefficient & 1.000 & $-.206^{* *}$ \\
& & Sig. (1-tailed) &. & .006 \\
\cline { 3 - 4 } & $\mathrm{N}$ & 150 & 150 \\
\cline { 2 - 4 } & & Correlation Coefficient & $-.206^{* *}$ & 1.000 \\
\cline { 2 - 4 } & & Sig. (1-tailed) & .006 &. \\
\cline { 2 - 4 } & $\mathrm{N}$ & 150 & 150 \\
\hline
\end{tabular}

**. Correlation is significant at the 0.01 level (1-tailed).

Table 5.3 Correlation between emotional intelligence and anger

c. Relationship Satisfaction and Anger

A correlation analysis was done to find out if Relationship Satisfaction was significantly (negative correlation) related to Anger. The Spearman's rank correlation was calculated to find out the correlation between the variables. The Spearman's rank correlation, rho, can take a range of values from -1 to +1 . A value of 0 stipulates that there is no association between the two variables. A value greater than zero stipulates a positive association; that is, as the value of one variable increases, so does the value of the other variable. A value less than zero stipulates a negative association; that is as the value of one variable increases, the value of the other variable decreases. 
The correlation results were in line with the hypotheses. It was hypothesized that individuals who have a higher relationship satisfaction will show lesser anger. The correlation between the variables was found to be -0.130 which was significant at a $p=0.057$; which indicates a weak negative correlation.

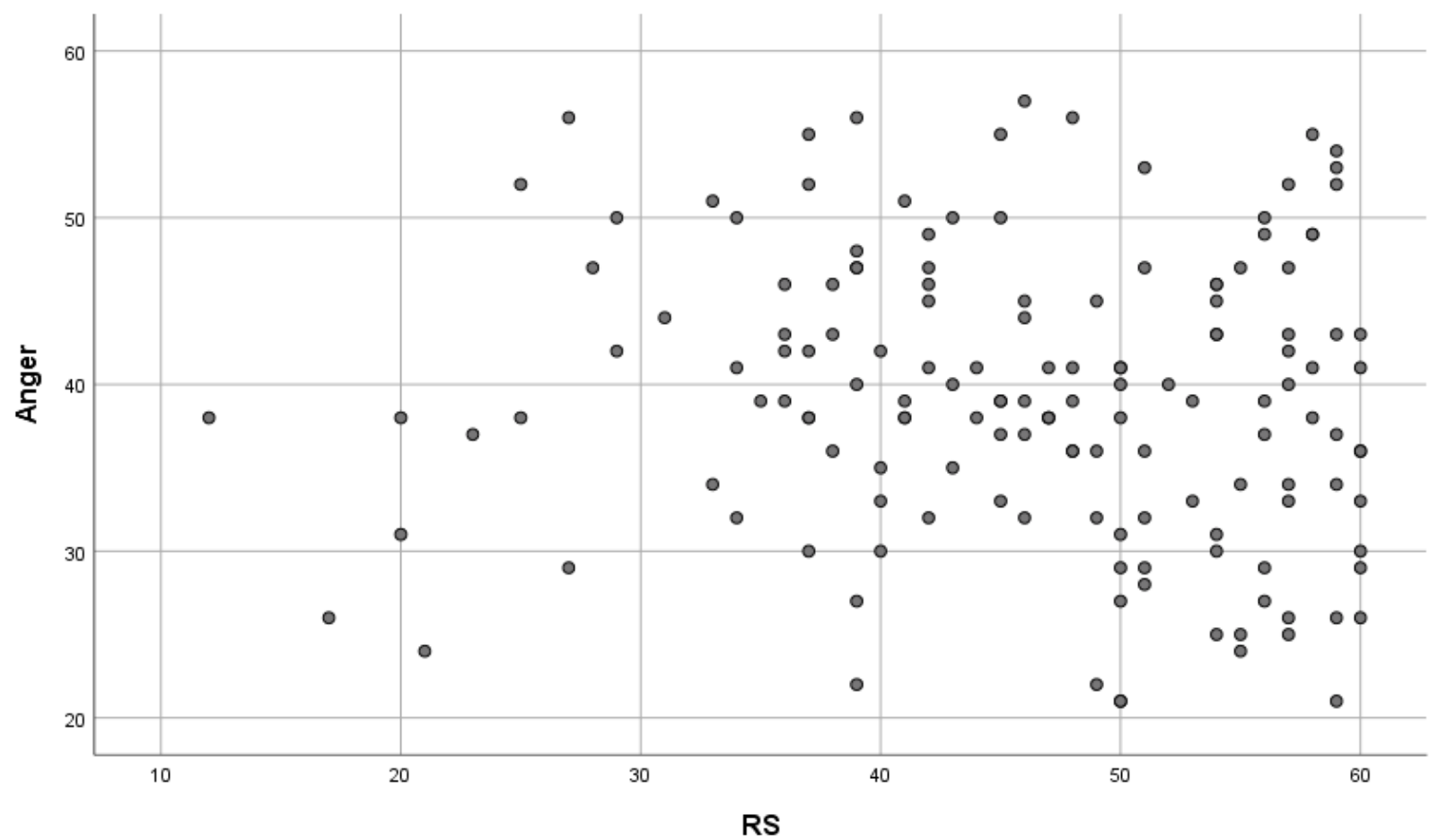

Fig 4.8 Scatter plot displaying the correlation between relationship satisfaction and anger

In a study by Renshaw et al., (Keith D. Renshaw, Rebecca K. Blais, 2010), results indicated that one's own anger and hostility were significantly related to a lower marital satisfaction [elf-report $\left(\chi^{2}\right.$ difference $\left.[1]=8.27, p<.01\right)$, partner-report $\left(\chi^{2}\right.$ difference $[1]=$ $9.84, p<.001)$, and the combinations $\left(\chi^{2}\right.$ difference $\left.\left.[1]=13.77, p<.001\right)\right]$. 
38 Emotional Intelligence, Relationship Satisfaction and Anger.

Correlation

\begin{tabular}{|c|c|c|c|c|}
\hline & & & $\mathrm{RS}$ & $\mathrm{AG}$ \\
\hline \multirow[t]{6}{*}{ Spearman's rho } & \multirow[t]{3}{*}{$\mathrm{RS}$} & Correlation Coefficient & 1.000 & -.130 \\
\hline & & Sig. (1-tailed) & & .057 \\
\hline & & $\mathrm{N}$ & 150 & 150 \\
\hline & \multirow[t]{3}{*}{$\mathrm{AG}$} & Correlation Coefficient & -.130 & 1.000 \\
\hline & & Sig. (1-tailed) & .057 & \\
\hline & & $\mathrm{N}$ & 150 & 150 \\
\hline
\end{tabular}

Table 5.4 Correlation between relationship satisfaction and anger. 


\section{Summary and Conclusion}

\subsection{Summary of the study}

This study was conducted to examine the relationship between emotional intelligence, relationship satisfaction and anger on adults. The scales deployed in the study were administered to adults between the ages of 25 and 60 years. For the interpretation of the collected data, statistical tools were employed. The Spearman's correlation was computed using the R and SPSS Software. The hypotheses of this study were then validated based on the obtained data. The results were in line with the hypothesis wherein; emotional intelligence and relationship satisfaction were positively correlated, emotional intelligence and anger were negatively correlated and relationship satisfaction and anger were negatively correlated. The statistical data also showed a positive correlation between the four aspects of emotional intelligence and relationship satisfaction. The results of this study indicate how higher emotional intelligence can yield higher relationship satisfaction.

\subsection{Limitations of the study}

The small sample size of this study can be a major drawback as it does not represent the entire population. The Sampling methods used in this study are convenience sampling with the snowball method. This sampling method has drawbacks as the sample is not representative of the entire population and therefore this might affect the results. 
The study also examined only emotional intelligence and anger as a variable of relationship satisfaction whereas a lot more factors are accountable in the case of satisfaction in a relationship. The study was limited to a small sample with a limited number of demographic variables. The male to female ratio in the study was small and that can be taken into account in the future.

Self-reports to measure all three variables; emotional intelligence, relationship satisfaction and anger were employed, and thus similar positive or negative biases may have occurred in the three sets of ratings. Lastly, as the study was correlational in design, conclusions regarding causation cannot be drawn.

\subsection{Practical Implications of the Study}

This study helps researchers to understand the relationship between emotional intelligence, relationship satisfaction and anger. The study provided insights into the effects of emotional intelligence on relationship satisfaction and anger. The results of this study and many other researches done in the same field can be taken into consideration and can be used while understanding the effects of emotional intelligence on various aspects of the interpersonal lives of humans. This study examined two such aspects; relationship satisfaction and anger. 
By understanding the dynamics of the variables in this study, therapies can be planned for those who are in bad relationship due to various factors. This study examined the role of emotional intelligence on satisfaction in relationships and this can be kept in mind while planning interventions.

\subsection{Suggestions for Future Research}

Since this research was conducted on a small sample, future research can be conducted on larger group with more diverse population.

This study only examined two variables; relationship satisfaction and anger while examining the role of emotional intelligence. In the future, more variables related to interpersonal factors of humans can be studied and explored. 
Bibliography

A. Megias , R. Gomez-Leal, M.J. Gutierrez-Cobo, R. C., \& Fernandez-Berrocal, P. (2018). The relationship between aggression and ability emotional intelligence: The role of negative affect. https://doi.org/10.1016/j.psychres.2018.05.027

Bonneville, A. (2016). Intimate Partner Aggression and Relationship Satisfaction across Attachment Styles. https://ruor.uottawa.ca/bitstream/10393/35188/1/Bonneville_Alyssa_2016_thesis.pdf

Donald G. Dutton, Keith Saunders, Andrew Starzomski, K. B. (1994). Intimacy-Anger and Insecure Attachment as Precursors of Abuse in Intimate Relationships.

Faltas, I. (2017). Three Models of Emotional Intelligence.

Fehr, B., Baldwin, M., Collins, L., Patterson, S., \& Benditt, R. (1999). Anger in Close Relationships: An Interpersonal Script Analysis.

Ford, B. Q., \& Tamir, M. (2012). When getting angry is smart: Emotional preferences and emotional intelligence. Emotion. https://doi.org/10.1037/a0027149

Furnham, A., \& Petrides, K. V. (2003). TRAIT EMOTIONAL INTELLIGENCE AND HAPPINESS. Social Behavior and Personality: An International Journal, 31(8), 815823. https://doi.org/10.2224/sbp.2003.31.8.815

García-Sancho, E., Dhont, K., Salguero, J. M., \& Fernández-Berrocal, P. (2017). The personality basis of aggression: The mediating role of anger and the moderating role of emotional intelligence. Scandinavian Journal of Psychology. https://doi.org/10.1111/sjop.12367 
Garcia-Sancho, E., Salguero, J. M. \& Fernandez-Berrocal, P. (2017). Ability emotional intelligence and its relation to aggression across time and age groups. Scandinavian Journal of Psychology.

García-Sancho, E., Salguero, J. M., \& Fernández-Berrocal, P. (2014). Relationship between emotional intelligence and aggression: A systematic review. Aggression and Violent Behavior, 19(5), 584-591. https://doi.org/10.1016/j.avb.2014.07.007

Gottman, J. M., \& Krokoff, L. J. (1989). Marital Interaction and Satisfaction: A Longitudinal View.

Guerrero, L. K. (1994). “I'm So Mad I Could Scream:” The Effects of Anger Expression on Relational Satisfaction and Communication Competence. https://doi.org/10.1080/10417949409372931

Gun-Mette B Røsand, Kari Slinning, Malin Eberhard-Gran, E. R. \& K. T. (2012). The buffering effect of relationship satisfaction on emotional distress in couples. $B M C$ Public Health, 12(1). https://doi.org/10.1186/1471-2458-12-66

Hazan, C., \& Shaver, P. R. (1990). Love and work: An attachment-theoretical perspective. Journal of Personality and Social Psychology, 59(2), 270-280. https://doi.org/10.1037//0022-3514.59.2.270

Henriques Gregg. (n.d.). Differentiating Anger from Aggression. https://www.psychologytoday.com/us/blog/theory-knowledge/201501/differentiatinganger-aggression

Holtzworth-Munroe, A., Stuart, G. L., \& Hutchinson, G. (1997). Violent versus nonviolent 
husbands: Differences in attachment patterns, dependency, and jealousy. Journal of Family Psychology, 11(3), 314-331. https://doi.org/10.1037/0893-3200.11.3.314

Hülya ŞAHIN BALTACI, K. D. (2012). Pre-Service Classroom Teachers' Emotional Intelligence and Anger Expression Styles. In this study in which the pre-service classroom teachers' emotional intelligence and the ways of their anger expression styles were examined, correlational survey model was used. In total 342 students, 189 of whom were females and 153 of whom were males,

Keith D. Renshaw, Rebecca K. Blais, and T. W. S. (2010). Components of Negative Affectivity and Marital Satisfaction: The Importance of Actor and Partner Anger. https://doi.org/10.1016/j.jrp.2010.03.005

Kocur, J. L., \& Deffenbacher, J. L. (2014). Anger and Anger's Expression Generally and in Romantic Relationships.

Kopper, B. A., \& Epperson, D. L. (1991). Women and Anger: Sex and Sex-Role Comparisons in the Expression of Anger. Psychology of Women Quarterly, 15(1), 7-14. https://doi.org/10.1111/j.1471-6402.1991.tb00474.x

Lavalekar, A., Kulkarni, P., \& Jagtap, P. (2010). Emotional intelligence and marital satisfaction. Journal of Psychological Researches, 5(2), 185-194.

Liu, J., Lemay, E. P., \& Neal, A. M. (2018). Mutual Cyclical Anger in Romantic Relationships: Moderation by Agreeableness and Commitment. Journal of Research in Personality. https://doi.org/Liu, J., Lemay, E. P., \& Neal, A. M. (2018). Mutual Cyclical Anger in Romantic Relationships: Moderation by Agreeableness and Commitment. Journal of Research in Personality. doi:10.1016/j.jrp.2018.09.002 
Lynne Smith, Joseph Ciarrochi, P. C. L. H. (2008). The stability and change of trait emotional intelligence, conflict communication patterns, and relationship satisfaction: A one-year longitudinal study.

Lynne Smith, Patrick C.L. Heaven, J. C. (2008). Trait emotional intelligence, conflict communication patterns, and relationship satisfaction. https://doi.org/10.1016/j.paid.2007.11.024

Mayer, J. D., Salovey, P., Caruso, D. R., \& Sitarenios, G. (2001). Emotional Intelligence as a Standard Intelligence. Emotion, 1(3), 232-242. https://doi.org/10.1037/15283542.1.3.232

Petrides, K. V., \& Furnham, A. (2003). Trait Emotional Intelligence: Behavioural Validation in Two Studies of Emotion Recognition and Reactivity to Mood Induction. European Journal of Personality, 17(1), 39-57. https://doi.org/10.1002/per.466

Røysamb, E., Vitters $\varnothing$, J., \& Tambs, K. (2014). The relationship satisfaction scale Psychometric properties. Norsk Epidemiologi, 24(1-2), 187-194. https://doi.org/10.5324/nje.v24i1-2.1821

Sandra J. Bailey. (2011). Managing Anger for Better Health and Relationships. http://stillwater.msuextension.org/fcsmontguides/ManagingAnger.pdf

Schutte, N. S., Malouff, J. M., \& Bhullar, N. (2009). The Assessing Emotions Scale. 119-134. https://doi.org/10.1007/978-0-387-88370-0_7

Schutte, N. S., Malouff, J. M., Bobik, C., Coston, T. D., Greeson, C., Jedlicka, C., Rhodes, E., \& Wendorf, G. (2001). Emotional Intelligence and Interpersonal Relations. The 
Journal of Social Psychology, 141(4), 523-536.

https://doi.org/10.1080/00224540109600569

Sharkin et al. (1991). Anger Discomfort Scale. Evaluation, 1991.

Smith, L., Heaven, P. C. L., \& Ciarrochi, J. (2008). Trait emotional intelligence, conflict communication patterns, and relationship satisfaction. Personality and Individual Differences, 44(6), 1314-1325. https://doi.org/10.1016/j.paid.2007.11.024

Tejbeer Kaur and Gurminder Sokhey. (2011). Personality, Emotional Intelligence and Marital Satisfaction of Violent and Non-Violent Couples. Journal of the Indian Academy of Applied Psychology.

Vater, A., \& Schröder-Abé, M. (2015). Explaining the Link Between Personality and Relationship Satisfaction: Emotion Regulation and Interpersonal Behaviour in Conflict Discussions.

Zarch, Z. N., Marashi, S. M., \& Raji, H. (2014). The relationship between emotional intelligence and marital satisfaction: 10-year outcome of partners from three different economic levels. In Iranian Journal of Psychiatry (Vol. 9, Issue 4, pp. 188-196).

Zysberg, L., Kelmer, G., \& Mattar, L. (2019). Emotional Intelligence, Attachment and Satisfaction with Romantic Relationships among Young Adults: A Brief Report. 


\section{Appendix}

\section{A. Consent Form}

I, Ankita Pritamani, am conducting a research study on the relationship between Emotional Intelligence, Relationship Satisfaction and Anger in adults as a part of the curriculum of M.A. in Clinical PsychoIogy at Vivekanand Education Society, University of Mumbai. If you are between the ages of 25 and 60 , you are requested to respond to the given statements by choosing the options that are most applicable to you. All the responses shall be used for research purposes only and will be kept strictly confidential. This study would not cause any physical harm or other risks to the participants and if at any point, this study poses risk to your emotional or mental well being, you can withdraw your participation any time you wish. For any queries, you can get in touch with me at anki.pritamani@gmail.com.

Thank you for your participation.

I have read the details about the purpose of the study and therefore give my consent to be a part of this study.

○ Yes

○ No 
B. The Assessing Emotions Scale

Each of the following items asks you about certain variables. After deciding whether a statement is generally true for you, use the 5-point scale to respond to the statement. Please circle the " 1 " if you strongly disagree that this is like you, the " 2 " if you somewhat disagree that this is like you, " 3 " if you neither agree nor disagree that this is like you, the " 4 " if you somewhat agree that this is like you, and the "5" if you strongly agree that this is like you.

There are no right or wrong answers. Please give the response that best describes you.

$1=$ strongly disagree

$2=$ somewhat disagree

$3=$ neither agree nor disagree

$4=$ somewhat agree

$5=$ strongly agree

1. I know when to speak about my personal problems to others.

2. When I am faced with obstacles, I remember times I faced similar obstacles and overcame them.

3. I expect that I will do well on most things I try.

4. Other people find it easy to confide in me.

5. I find it hard to understand the non-verbal messages of other people.

6. Some of the major events of my life have led me to re-evaluate what is important and not important.

7. When my mood changes, I see new possibilities.

8. Emotions are one of the things that make my life worth living. 
9. I am aware of my emotions as I experience them.

10. I expect good things to happen.

11. I like to share my emotions with others.

12. When I experience a positive emotion, I know how to make it last.

13. I arrange events others enjoy.

14. I seek out activities that make me happy.

15. I am aware of the non-verbal messages I send to others.

16. I present myself in a way that makes a good impression on others.

17. When I am in a positive mood, solving problems is easy for me.

18. By looking at their facial expressions, I recognize the emotions people are experiencing.

19. I know why my emotions change.

20. When I am in a positive mood, I am able to come up with new ideas.

21. I have control over my emotions.

22. I easily recognize my emotions as I experience them.

23. I motivate myself by imagining a good outcome to tasks I take on.

24. I compliment others when they have done something well.

25. I am aware of the non-verbal messages other people send.

26. When another person tells me about an important event in his or her life, I almost feel as though I experienced this event myself.

27. When I feel a change in emotions, I tend to come up with new ideas.

28. When I am faced with a challenge, I give up because I believe I will fail.

29. I know what other people are feeling just by looking at them.

30. I help other people feel better when they are down.

31. I use good moods to help myself keep trying in the face of obstacles.

32. I can tell how people are feeling by listening to the tone of their voice.

33. It is difficult for me to understand why people feel the way they do. 


\section{Original Scale Instruction}

Each of the following items asks you about your emotions or reactions associated with emotions. After deciding whether a statement is generally true for you, use the 5-point scale to respond to the statement. Please circle the "1" if you strongly disagree that this is like you, the " 2 " if you somewhat disagree that this is like you, " 3 " if you neither agree nor disagree that this is like you, the "4" if you somewhat agree that this is like you, and the " 5 " if you strongly agree that this is like you.

There are no right or wrong answers. Please give the response that best describes you.

$$
\begin{aligned}
& 1=\text { strongly disagree } \\
& 2=\text { somewhat disagree } \\
& 3=\text { neither agree nor disagree } \\
& 4=\text { somewhat agree } \\
& 5=\text { strongly agree }
\end{aligned}
$$


C. The Relationship Satisfaction Scale

Please mark the answer for each item which best answers that item for you.

1- Strongly Disagree

2- Slightly Disagree

3- Disagree

4- Agree

5- Slightly Agree

6- Strongly Agree

1. I have a close relationship with my spouse/partner

2. My partner and I have problems in our relationship

3. I am very happy with our relationship

4. My partner is generally understanding

5. I often consider ending our relationship

6. I am satisfied with my relationship with my partner

7. We frequently disagree on important decisions

8. I have been lucky in my choice of a partner

9. We agree on how children should be raised

10. I think my partner is satisfied with our relationship 
D. The Anger Discomfort Scale

Following are a number of statements that people may use to describe themselves. Read each statement and then, using the scale below, choose the number that best indicates how you generally feel. There are no right or wrong answers. Do not spend too much time on any one statement but give the answer that seems to describe how you generally feel.

$1=$ Almost Never

$2=$ Sometimes

$3=$ Often

$4=$ Almost Always

1. I do not like it when I get angry.

2. I feel guilty about being angry at others.

3. I fear that my anger will hurt other people.

4. I would prefer that people not see me when I am angry.

5. I believe that it is natural and healthy to feel angry.

6. I am troubled by my anger.

7. People do not seem to like me when I am angry.

8. I create more problems for myself when I get angry.

9. I should not be angry as often as I am. 
53|Emotional Intelligence, Relationship Satisfaction and A n g e r.

10. I believe that it is acceptable for people to feel anger.

11. I feel comfortable with my angry feelings.

12. When I get angry, I also get nervous.

13. My anger scares me.

14. I am embarrassed when I get angry.

15. I fear losing control because of my anger. 